\title{
ВЛИЯНИЕ ЗАПАДНОГО КУЛЬТУРНОГО МЬШЛЕНИЯ ПОСТМОДЕРНИЗМА НА КИТАЙСКОЕ ТРАДИЦИОННОЕ ИСКУССТВО
}

\section{THE IMPACT OF WESTERN CULTURAL THINKING ON POSTMODERNISM ON CHINESE TRADITIONAL ART}

\section{Guo Tingting}

Summary: Globalization is have a form of worldwide cultural integration. Natiotal cultures can use it for exchange of experience, innovation and cultural achievements. National cultures face the problem of maintaining their identity. The article discusses how the culture of China interacts with the processes of globalization and analyzes the ongoing processes and future trends.

Keywords: China, art, culture, cultural exchange, globalization postmodern.
K итайская художественная культура имеет долгую историю. Художественные произведения китайского традиционного искусства содержат в себе проявления социальных форм и духовной жизни своих эпох. Произведения китайского традиционного искусства не только знакомят людей с различными формами искусства разных эпох истории Китая, но, также, и демонстрируют людям историю китайской культуры. По мере развития общества, непрерывно видоизменяется культурный и моральный облик людей, и сейчас, китайское традиционное искусство, несет в себе как огромный пласт древнейшей национальной культуры, так и новые веяния западного мышления постмодернизма, представляя собой нечто новое, уникальное и прекрасное.

Но что мы вкладываем в само понятие «мышление постмодернизма»? Определение несколько разнится в зависимости от контекста, но если смотреть широко, то постмодернисткое мышление представляется как незавершенный и нестабильный набор положений, который возникал постепенно под влиянием разнообразных интеллектуальных и культурных течений: от прагматизма, экзистенциализма и психоанализа до феминизма, герменевтики, постэмпирической философии науки и многого другого. Из совокупности всех этих тенденций и течений сложилось определенное количество принципов, ставших ведущими для термина «мышление постмодернизма». Так, стали цениться гибкость и постоянное изменение действительности и знания, предпочтительным становится конкретный опыт в сравнении с отвлеченными принципами. Появляется убежденность в том, что ни

\author{
Го Тинтин \\ Аспирант, Государственный университет управления \\ ting19881229@126.com
}

Аннотация: Идущая глобализация проявляется в форме всемирной культурной интеграции. Для национальных культур этот процесс полезен, потому что позволяет обмениваться опытом, инновациями, достижениями. Однако, перед национальными культурами встает проблема сохранения своей идентичности. В статье рассмотрено, как культура Китая взаимодействует с процессами глобализации, анализируются происходящие процессы и выясняются тенденции развития.

Ключевые слова: Китай, искусство, культура, культурный обмен, глобализация, постмодернизм.

одна априорная система мысли не должна тяготеть над воззреᄀниями или исследованиями человека. Становит-

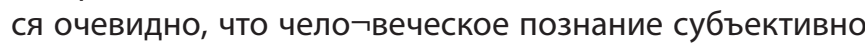
и определяется множеством различных факторов, что объективная сущность, или вещь должна постоянно переосмысливаться и подвергаться проверке. Именно поэтому, приобретение знаний должно стать бесконечным пересмотром их. Смысл в том, чтобы пробовать все новое, экспериментировать и исследовать - в этом и заключается смысл мышления постмодернизма. Так каким же образом подобное западное мышление повлияло на традиционное китайское искусство?

В первую очередь, под влиянием глобализации появилась тенденция к росту уровня культуры населения, что, в свою очередь, поспособствовало развитию институций искусства. Западное мышление постмодернизма, проникая в Китай, расширило привычные границы творчества, оно начало принимать все более и более разнообразные формы. Под влиянием западного мышления постмодернизма, институции искусства в Китае, как государственные, так и частные, начинают развиваться беспрецедентными темпами.

Так, в Китае, под влиянием западного искусства постмодернизма было в короткие сроки создано несколько публичных художественных галерей, в том числе мемориальный зал «Сюй Бэйхун», Цзянсуский областной художественный выставочный зал и Шанхайский выставочный зал изобразительных искусств. А после принятия правительством Китая политики «реформ и откры- 
тости», ситуация с развитием художественных галерей в Китае стала стабильно улучшаться.

Согласно статистике, в 2012 году в реестре Национальной культурной системы Китая было 265 музеев. Даже сегодня во многих провинциях в центральных и западных районах Китая по-прежнему нет провинциальных художественных музеев. Кроме того, не все публичные художественные музеи в Китае имеют условия для выставок именно современного искусства. После середины 80-х годов количество публичных художественных музеев в Китае быстро росло. Но, к сожалению, отечественная коллекция современного искусства все еще находится в развивающемся состоянии.

На данный момент, в Китайском художественном музее собрано более 100000 произведений искусства разных видов. В коллекции доминируют произведения искусства китайских мастеров самых разных периодов, с конца 19 века до наших дней. Кроме музеев национального уровня, нужно отметить несколько музеев искусств провинциального уровня, считающихся лучшими среди публичных художественных галерей страны. Из них, нужно отметить Гуандунский художественный музей, в коллекции которого находится много работ современного китайского искусства, навеянного западным мышлением постмодернизма и немалое внимание уделено произведениям живущих за рубежом китайцев. Основное внимание уделяется современному искусству китайского побережья и современному искусству Гуандун. Коллекция в основном состоит из картин, скульптур и керамики, кроме того есть коллекция исторических предметов культуры различных категорий искусства и связанных с ними книг и документации эпохи Древнего Китая.

Кроме Музея искусств Гуандуна, нужно отметить Шэньчжэньский художественный музей и Художественный музей Хэсяньнин, которые тоже считаются музеями с богатыми коллекциями современного китайского искусства. В мае 2013 года в Художественном музее Хэ Сяньнин состоялась «Выставка современного искусства». Эта выставка включала работы Юэ Миньюна и Суй Цзяньго, а так же произведения многих других авторов. Эти авторы, работающие в ключе современного искусства, имеют важное значение для современного китайского искусства. Они не только обогатили коллекцию Художественного музея Хэ Сяннин, но и имеют большее практическое значение. По сравнению с этими прибрежными художественными музеями, участвующими в коллекционировании предметов современного искусства, коллекции современного искусства в провинциальных публичных художественных музеях во внутренних районах Китая относительно скудны.

В Шанхайском музее искусств собрано около 10000 работ. В нем собраны произведения известных художников Шанхая и картины, выполненные в таких техниках, как картины маслом, комиксы и картины в ключе современного искусства. В последние годы Шанхайское муниципальное правительство вносит большой вклад в развитие сотрудничества с художественными галереями в Лувре, Музее изобразительных искусств Орсе и Центре современного искусства Помпиду во Франции. Выставляемые там коллекции демонстрируют историю древнего и современного искусства Китая. Этому способствуют общественные художественные музеи, такие как Шанхайский музей, Китайский дворец искусств и Шанхайский музей современного искусства: Шанхайский музей демонстрирует древнее искусство, Китайский художественный дворец и Шанхайский музей современного искусства демонстрируют произведения в рамках современного искусства постмодернизма. Шанхайский музей современного искусства, - единственный публичный музей современного искусства в Китае, в течение трех лет также провел множество важных выставок современного искусства, например как: «Создание в Китае - тридцать лет современного китайского искусства» и «Обзор Энди Уорхола», а также другие выставки современного искусства. Но поскольку, музей только создается, коллекция еще не очень богата.

Институции искусства важны в областях образования, отдыха и развлечений, что очень важно для людей, и влечет потребность в качественных выставках. И, в то же время, отношения между институциями искусства, креативной индустрией, региональной экономикой и культурным туризмом становятся все более близкими.

После середины 80-х годов, в Китае начался бум создания общественных галерей и музеев искусства. Снова появился интерес к строительству художественных музеев. Культура вступила в очередной этап своего развития. Ситуация создания большого количества новых учреждений и развития художественных академий, помимо компенсации отсутствия местной музейной системы, также требует, чтобы художественные музеи и галереи отказались от своей изначальной роли простой выставки и приблизились к функционалу, характерному для международного художественного музея. Таким образом, в течение 20-30-и лет, были созданы новые места для публичных выставок и образования в сфере культуры.

Культурная активность 1980-х гг. преимущественно представляла собой международный диалог. Постмодернистское искусство в Китае проходило становление, опираясь на западный образец, именно в этот период появились многочисленные сообщества молодых художников, и вскоре в художественной жизни страны были представлены уже почти все направления современного западного искусства постмодернизма. После 
окончания проводившейся в 1989 г. «Выставки современного китайского искусства», в современном искусстве Китая наступило время расцвета разнообразных стилей и направлений.

Искусство этого периода оказывало стимулирующее воздействие на процессы раскрепощения сознания, шедшие в Китае под влияние западного мышления постмодернизма. Оно стало связующим звеном с западным искусством и его концепциями, поставив под сомнение и атаковав традиционные культурные устои, складывавшиеся в Китае на протяжении огромного временного периода. Кроме того, оно дало новый язык и концепции для современного искусства, заложило исторический фундамент для его развития.

В период с 1995 по 1997 годы, в провинции Гуандун были созданы Художественный музей Хэ Сяннин, Художественный музей Гуаншаньюй и Музей искусств Гуандуна. Это стало знаменательным событием в преобразовании китайской институции искусства нового периода.

В конце 1990-х годов в Китае был экспериментальный период строительства частных художественных галерей, таких как Музей искусств Шанхэ в Чэнду и Художественный музей Донгю в Шеньяне, но ни один из этих музеев не смог успешно работать. Около 2003 года в Китае было повторно создано множество частных художественных галерей. Но только несколько учреждений, таких как Музей современного искусства «Сегодня в Пекине», Музей современного искусства Шанхая «Зендай» и Центр современного искусства «Шэньчжэнь» успешно работают до нынешнего момента.

1990-1999 гг. представляет собой время взросления современного китайского искусства. В 90-ые продвигаясь по пути реформ и открытости и развития рыночной экономики, условия для развития искусства изменялись в позитивную сторону, что оказало весомое влияние и изменило выразительные средства и формы искусства. Страна была открыта для западной экономики, науки и техники, что повлекло за собой внедрение западных ценностей и концепций, оказавших большое влияние на китайскую культуру. В отличие от существовавшего до этого, продиктованного языком авторитаризма своего рода однообразия, в 90-ые годы 20-ого века в Китае расцветали все направления, стили и техники.

В 90-х годах в Китае, художественные стили национального традиционного искусства, такие как китайская живопись, картины тушью и т.д., и привнесенные жанры китайского изобразительного искусства (живопись маслом, скульптура) постепенно видоизменяются. Появляются новые направления искусства - политическое искусство, цинический реализм, женское искусство, и т.д.
Отличные от традиционных формы искусства, появившиеся исключительно под влиянием западного мышления постмодернизма, стали возможными в эпоху расцвета китайского современного искусства. В Китае, наконец, появились авторы, работающие в таких жанрах, как инсталляция, перформанс, концептуальное искусство, видео-арт и т.д. Большая часть зрительской аудитории Китая зрелого возраста не воспринимает эти авангардные направления в искусстве как способные чем-то обогатить искусство Китая. Их считают просто временным социальным явлением, критикуют, но, тем не менее, они вызывают интерес и становятся частью современного китайского искусства. Среди молодежи же, все эти направления крайне популярны.

В начале 21 века, когда миром стала править экономическая глобализация, а Китай вступил в ВТО, ему в невиданных ранее масштабах пришлось столкнуться с западным мышлением и культурой, что повлекло новые вызовы. Столкновение китайской культуры с культурами других стран в процессе культурного обмена естественным образом порождает определенные противоречия, но культурные различия стран и народов преодолеваются со временем, сливаются в единый культурный поток, составными частями которого будут являться традиционные национальные культуры. Взаимодействие современного китайского искусства и пришедшего в Китай влияния постмодернистского искусства Запада - сложный и противоречивый процесс интеграции, но на данный момент состояние современного китайского искусства прошло через стадии имитации, поглощения и использования трансформирования инноваций, что и поспособствовало его нынешнему разнообразию.

В настоящее время на материке насчитывается более 1000 художественных галерей и музеев. Но только 30 из них действительно соответствуют профессиональным стандартам художественных музеев. Большинство из них сосредоточено в Пекине, Шанхае, Шаньдуне, Цзянсу, Чжэцзяне и других прибрежных районах. Современные музеи должны отражать региональные характеристики и особенности. Художественные музеи и галереи в таких прибрежных районах, как Шаньдун, Цзянсу и Чжэцзян, в основном посвящены каллиграфии и живописи. Художественные галереи и музеи с преобладающей долей современного искусства, таким, как масляная живопись, сосредоточены главным образом в районе Пекина и Шанхая. Кроме того, в регионах акцент делается на местных художников. Подобный подход - тенденция основного направление развития институций китайского искусства, при котором крупные города имеют определенную степень перспективного развития, в то время как региональные города относительно консервативны.

Сейчас Китай входит в «эпоху музейного искусства». Возник всплеск интереса к строительству художествен- 
ных музеев по всей стране, и государственные художественные музеи и частные художественные музеи получили хороший импульс для развития. Акцент в политике страны на культуру и искусство, вместе с процветанием арт-рынка и наличием сильных эстетических потребностей народных масс также служит источником дополнительного импульса для развития музеев. Сейчас стало модно посещать выставки и участвовать в мероприятиях в художественных музеях. В настоящее время развитие Китайского художественного музея приближается к уровню международного сообщества. Китайский художественный музей, собравший более 100000 произведений изобразительного искусства, работает с произведениями искусства периода до и после основания Нового Китая, а также хранит шедевры художников династии Минь, династии Цин и Китайской Республики. Коллекции - это в основном прекрасные произведения современного искусства, репрезентативные произведения известных китайских современных художников, отмеченные наградами произведения крупных художественных выставок и произведения народного творчества. Среди коллекций - работы Рэна Бояна, У Чаншуо, Хуан Биньхона, Ци Байши, Сюй Бэйхун, Цзян Цзаохэ, Си Цяо, Ли Керана, У Цзоорена, Е Цяню, Ло Гунлю, У Гуаньчжун и других авторов. Существует множество коллекций, начиная от традиционной каллиграфии и живописи, вплоть до самых современных видов искусства. Коллекции включают в себя десятки категорий, таких как картины, скульптуры, предметы народного искусства в керамике и т.д. В том числе в этот список включены новогодние картины, резаная бумага, игрушки, предметы искусства тени, художественные изделия из пластика, интерактивные кукольные спектакли и куклы, воздушные змеи, народная живопись, вышивка и другие виды искусства. Людвиг, немецкий коллекционер, пожертвовал 117 произведений европейского и американского международного искусства, в том числе 4 произведения Пикассо для коллекции искусства в музее. Это первая коллекция западных произведений искусства в Китае, но помимо нее есть сотни предметов африканской резьбы по дереву и других зарубежных произведений искусства.

Китайский художественный музей организовал тысячи влиятельных художественных выставок и выставок всемирно известных художников. Наряду с про- ведением важных национальных выставок наиболее заметными международными выставками являются: «Оригинальный 500-летний шедевр картин Хаммера», «Выставка живописи о сельской местности Франции 19 века», «Оригинальная выставка живописи Пикассо», «Выставка экспрессионизма и импрессионизма Германии», «Художественная выставка Родана», «Художественная выставка Шагала», «Мировая выставка духовного искусства мира», «Выставка коллекций австралийских национальных музеев», «Выставка африканского искусства», «Дали», «Французская выставка импрессионистических картин и сокровищ», «Летняя Франция - Пекин», «300 лет русского искусства - Государственная Третьяковская гарелея» (одна из крупнейших выставок «Года русской культуры в Китае» в 2006 году), «Триста лет американского искусства: адаптация и инновации», «Итальянское искусство и итальянская жизнь» (одна из крупнейших выставок «Года Италии в Китае» в 2006 году), Художественная выставка «Коллекции с собрания Тициана до Гойи», (Одна из главных выставок «Года испанской культуры» в 2007 году»).

Постепенно в область искусства приходят значительные инвестиции, что способствует появлению новых художественных музеев, кроме того, на территорию материкового Китай приходят музеи зарубежного искусства. Музеи позволяют рынку китайского искусства стать частью международного, профессионального и стандартизированного рынка искусства. Все это стало возможным благодаря проникновению в Китай западного мышления постмодернизма, новых веяний, новых тенденций. Но в то же время, как видно из вышесказанного, большое внимание уделяется и сохранению древней национальной культуры Китая.

Китайское национальное искусство невероятно аутентично и представляет огромную ценность для нации. Оно базируется на традиционной национальной культуре, отражает жизнь народа Китая и проблемы китайского общества. Традиционному искусству Китая не страшны никакие новые веяния, они только привнесут хорошее и сделают традиционное искусство свободнее и разнообразнее, сохранив при этом национальную суть и древние традиции.

\section{ЛИТЕРАТУРА}

1. Андреева, Е.Ю. Постмодернизм - искусство второй половины XX - начала XXI века / Е.Ю. Андреева. - Санкт-Петербург: ИВ Ивана Лимбаха, 2007г. - 867 с.

2. Минлу Гао. История китайского современного изобразительного искусства / Гао Минлу. - Шанхай, 1991г. - 662 с.

3. Минлу Гао. Китайское авангарное искусство / Гао Минлу. - Нанкин, 1997 г. - 432 с. Вихрова А.Ю., Юймэн В. Сотрудничество в сфере образования как форма культурного обмена между Китаем и Россией // Проблемы науки. - 2016. - № 9 (10). - С. 45-58.

4. Сяньтин Ли. История современного изобразительного искусства 1985-1989 / Ли Сяньтин. - Чанша, 1991 г. - 328 с.

5. Пэн Люй. История китайского искусства 20 века / Люй Пэн. - Пекин, 2007 г. - 957 с. 
6. Хун Лу. Китайское современное искусство: 1979-1999 концептуальное искусство / Лу Хун. - Ухань, 2001г. - 464 с.

7. Ц Цзы Дао. Системы искусства постмодернизма / Дао Цзы. - Чунцин, 2001г. - 644 с.

8. Шоучжи Ван. История мирового современного искусства / Ван Шоучжи. - Пекин: Веяние искусства, 2005г. - 368 с.

9. Юйлинь Цао. Изменение облика современной китайской живописи / Цао Юйлинь. - Шанхай, 2006г. -218 с

10. Юецзинь Цзоу. Другой взгляд западизм в современном искусстве / Цзоу Юецзинь. - Пекин, 1996г. - 264 с.

11. Юецзинь Цзоу. История изобразительного искусства Нового Китая 1949-2000 / Цзоу Юецзинь. - Чанша, 2002г.- 398 с.

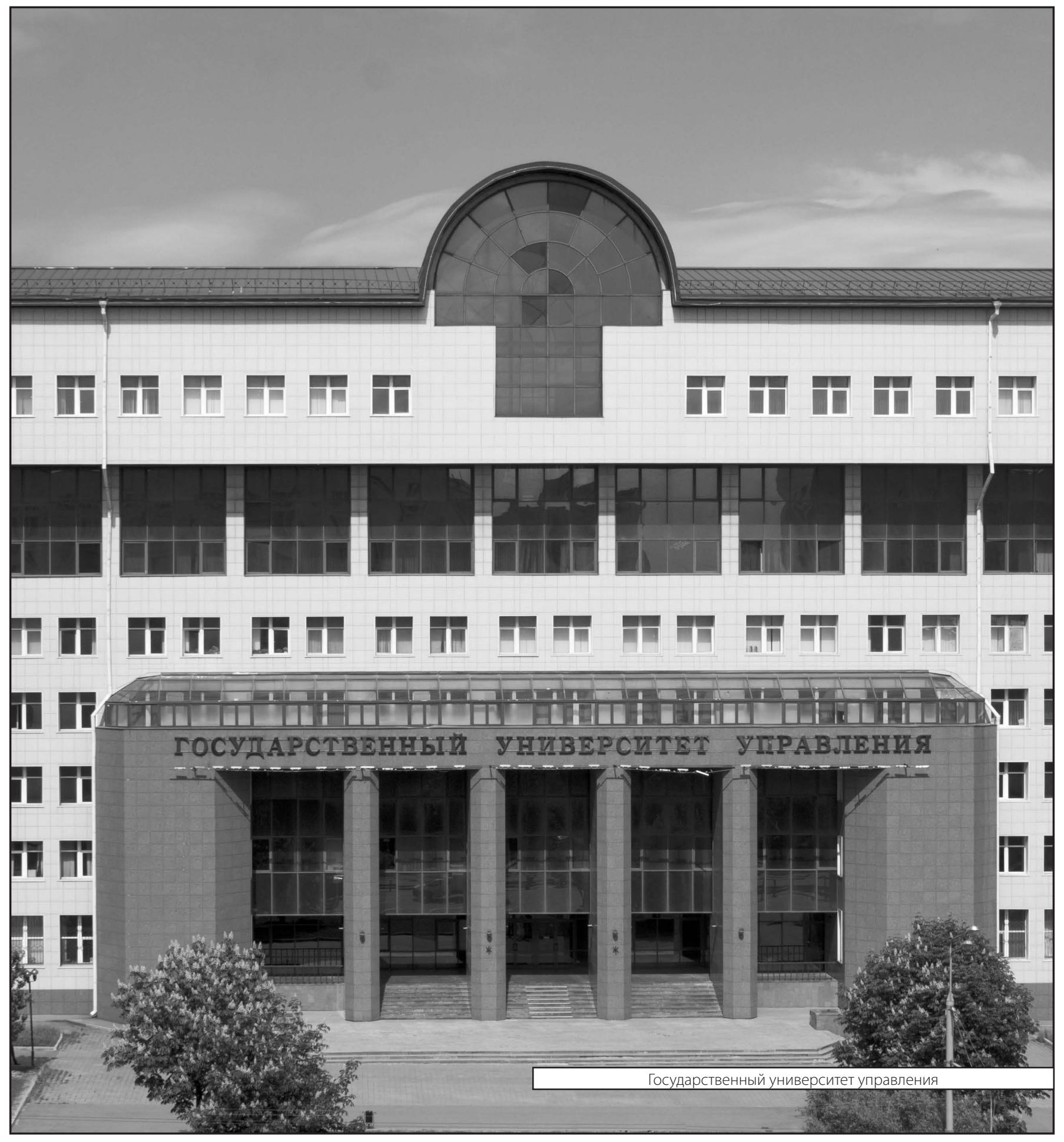

